\title{
FROM PUDDING TO PROMAJA: NAVIGATING THE CULTURAL LABYRINTH OF LIVING AND TEACHING IN SERBIA
}

\begin{abstract}
Having arrived to teach at Belgrade University's English Department as a mere twentysomething, fresh from my own undergraduate studies in England, I have spent the majority of my adult life in Serbia, experiencing the local culture in all its glory, but very much through the eyes of someone who grew up immersed in British culture. In this paper, I will recount some of the most noticeable and memorable cultural differences encountered over the years. I will then focus on the integral nature culture plays in my English language teaching at the English Department, the cultural 'difficulties' faced by students past and present, and the direction I think the 'cultural aspect' of EFL teaching at university level should take in the future, with particular focus on Belgrade University's Faculty of Philology.
\end{abstract}

Key words: English-Serbian cultural differences, Belgrade University's English Department, future trends in EFL teaching at university level

\section{A trip of a lifetime? No, a trip for a lifetime!}

It certainly wasn't planned. It was more of a 'well, I've got nothing better to do' moment. A gap year spent volunteering on a refugee camp in the lush green hills of Slovenia while war was tearing the rest of Yugoslavia apart seemed like something so far removed from my reality, from something I would find myself doing, that the plane journey felt like an out-of-body experience. It was, though, an experience that would very much change my reality.

That year, 1993, was my first experience of the Balkans and strangely enough, at the age of 18, my first experience of coffee. I was used to seeing friends with steaming mugs of Nescafe, but the rather rotund Bosnian lady, mother to six children who entertained themselves by scampering around one of the rather cramped dorms of what used to be an army barracks, proudly presented me with a thimbleful of the local 'Turkish' coffee. I looked at the tiny cup and then at her, she looked at me, and I knocked the drink back in one go. She hesitated before spinning around and

\footnotetext{
*Faculty of Philology, Department of English, Studentski trg 3, 11000 Belgrade, Serbia; email: jon_ pendlebury@hotmail.com
} 
hurrying off to make another one. I downed that one in a single gulp, too... and was promptly presented with another. And so it went on. Twenty minutes and nine coffees later, with my host's eyes agoggle, I tried to get to my feet, but quickly sat down, the room spinning like a scene from Alice in Wonderland, much to the mirth of all those looking on. Not only was it my first experience of caffeine, but my first cultural misunderstanding, and yet on both sides there was an awareness and an attempt to satisfy the other's cultural norms - 'this must be how they do it where they're from'.

In fact, the whole year was certainly a culture shock, but I didn't know how much was down to the stressful environment these unfortunate people found themselves in and how much was just 'Yugoslavia'. Whatever the case, a flame was lit inside me, mainly driven by the positive, 'glass half full' attitude of the people I encountered, and having graduated from Nottingham University and ignored my parents' advice never to be a teacher, I returned to the Balkans in 1997 to take up a teaching position at the English Department at Belgrade University's Faculty of Philology, and was faced with yet more cultural differences within the first ten minutes of setting foot on Serbian soil.

The exact date of my arrival was $31^{\text {st }}$ August 1997 - the same day that Diana, Princess of Wales lost her life in a car accident in Paris. I'd decided to take a taxi from Belgrade's airport and while sitting pensively, taking in my new surroundings, the rather morose taxi driver asked me where I was from. Upon learning I'd flown in from England, he perked up a bit and asked bluntly, "So, who did it?" My blank look prompted him to explain. He was convinced the princess had been assassinated - the thought had never occurred to me - and proceeded to present me with an astonishing array of theories. There was no persuading him otherwise. This was my introduction to the Serbian conspiracy theory and I didn't know then what a key part of the mentality it is: the national football team lose 5-0, it's the referee's fault, you turn up to work late for the fifteenth day in a row despite repeated warnings and are promptly sacked, it's the boss who doesn't like you, a student fails an exam for the third time, it's because the teacher has it in for him/her.

My new home soon provided me with one of very few cultural disappointments. Now, I'm a Yorkshire lad, used to hearty dinners followed by equally hearty deserts - the stodgier, the better is my motto. Apple crumble and custard, rhubarb fool, trifle, lemon meringue pie, sticky toffee pudding, Manchester tart, Eton mess - the list of puddings I grew up with is endless. So you can imagine how my heart sank when, having been offered puding by a friend's mother (pity was shown to me on regular occasions in my first couple of years in Belgrade and I was frequently wined and dined by my new-found friends and their mothers), she proudly presented me with a measly bowl of blancmange. This is the lofty heights Serbian desserts reach. Bizarrely, my waistline has expanded during my time in Serbia - maybe it's the lack of a decent pudding that's to blame (crikey, did that sound like a conspiracy theory?!) 
Anyway, my concerns about a potential lack of sugar and stodge in my diet were soon put into perspective when I came face to face with, by all accounts, the biggest threat to humanity. I spent my first couple of years in Belgrade living in a student hall of residence with the other foreign language instructors. It was great fun and we mingled with the students (playing the guitar and Riziko in the evenings at curious gatherings called sedeljka which were advertised as parties, but more involved sitting around in a circle chatting). As in any such place, there was definitely a self-imposed student hierarchy and the 'top dog' was a huge, hirsute guy who merely had to glare at his underlings for them to fall in line. One morning, as I wandered, slightly blearyeyed to breakfast, I was greeted by the sight of the main man running about shouting, "Ubice nas promaja! Ubiće nas promaja!" My limited Serbian at the time was still good enough to realise my life was in imminent danger - "Promaja will kill us!" I assumed Mr. Promaja (pronounced promaya) was armed to the teeth and turned on my heels and fled. I hid under my bed and called a friend in a terrible panic, pleading with him to send in the Special Forces to rescue us all. In gales of laughter, he explained promaja means draught. Now in England, 'airing the room' is seen as a positive thing and a bit of a breeze blows the cobwebs away. Apparently, in the Balkans, the sight of an open window opposite an open door (even inside a sweltering trolleybus at the height of summer) strikes fear into the soul and sends people diving for cover. Even sitting beneath an air conditioning unit will potentially have fatal consequences. It taught me that some words are simply untranslatable... promaja sounds so much more fearsome than draught! Certainly, if I ever feel my students' energy levels dropping in class, I fling open the windows and door, and there's instantly a flurry of activity as they grab their coats and pull their hoods over their heads.

Other threats to one's physical well-being include walking barefoot. "You'll never become a father," I was warned while walking on some kitchen tiles without my shoes and socks on just as my three children burst into the room. I'm frequently glared at, too, while sitting on concrete steps. Random passers-by show genuine concern as they try to push their newspaper or a piece of cardboard under my derriere. Apparently, such reckless behaviour will give me haemorrhoids... though to date I've only suffered from the occasional piece of chewing gum stuck to the seat of my trousers. Different cultures and completely different takes on the events of everyday life. I began to realise my teaching wasn't just going to be about the language, but that developing learners' cultural awareness was almost just as important.

There are, naturally, many other cultural differences I could mention: over-thetop generosity, which involves feeding guests until they're fit to burst; using a litre of cooking oil every couple of weeks; a very sombre attitude to death and funerals (bizarrely, often accompanied by a meal at the graveside); parking wherever one can 
find room, even if this means pavements are turned into makeshift car parks, meaning pedestrians have to take their lives in their hands as they walk along the carriageway; what (not) to talk about at the dining table, which has resulted in bruised shins on many occasions; a fascination with Shakespeare that is far more pronounced than the English have; being, supposedly, devoutly religious and yet incredibly superstitious. And, of course, in line with the conspiracy theory trait, there's the 'blame game'. In my experience, and of course, I am generalising, the Serbs rarely blame themselves.

After many years of playing rugby in England, I was delighted to find a team to play with in Belgrade. I thoroughly enjoyed the camaraderie, but was distraught as we never finished a match with a full complement of players on the pitch. It had been drilled into us from when we first held a rugby ball in our hands to address the referee with 'Yes, Sir!' and any straying from this phrase (even when you were seething inside at the perceived injustice over the whistle-blower's wrong decision) would result in press-ups, sit-ups and sprints galore as a punishment once the game was over. The matches in Serbia degenerated into players yelling at each other and the referee, whenever a mistake was made; inevitably a physical fight ensued and red cards were dished out like desserts in England. Every mistake was always someone else's fault. But it was a useful lesson for my teaching. It's always my fault! Every bad mark, every occasion an exam is not passed, every piece of homework not done - somehow it's down to me. So, when teaching, I consider it part of my job to encourage students to self-analyse, to think about what they could do better next time rather than going down the 'conspiracy theory' route. It's crucial and without it there can be no way forward. It still amazes me that when a student fails an exam, they don't come to see their paper to find out why they failed, to see how they can improve, what they can do differently.

Probably the most important cultural difference, certainly when it comes to the way we use language, is the British insistence on what can only be described as 'overpoliteness'. I once witnessed a man tread on someone's foot in a lift in England. The 'victim' apologised ("Sorry!") and the miscreant swiftly removed their foot with a "That's OK." It is something that is drilled into us from an early age in England saying your pleases and thank yous, laboriously writing thank-you notes for Christmas presents (rather taking the shine off the toys you've received), saying sorry for almost anything, and saying something is delicious even when you are struggling to swallow it. And it was the latter that got me into trouble.

There is a delicacy in these parts known as pihtija. It's a glorified form of aspic, usually with a miniscule amount of meat and carrot and a disproportionate quantity of jelly. It's commonly served at saint's day celebrations when friends and family gather together at the host's house to pay homage to their family saint. A good friend had invited me to her home in the town of Zaječar to celebrate Saint Luke's Day and, as was frequently the case at such events, I found myself the centre of attention - as one 
of the few foreigners in Belgrade in the late 1990s, I was something of a curiosity. Her father proudly brought out a plate of pihtija and asked me whether I had ever tried it. Remembering my 'polite' English heritage, I replied I hadn't, but that I would love to, even though the wobbling savoury mass before me looked suspiciously unpalatable. I gingerly took a tiny piece with my fork. The onlookers gasped at my modesty and my friend's father said, "No, no! You must try it properly!" before serving me with half the plate. With twenty pairs of eyes staring intently, I barely managed to get it down, but, true to my English roots, I announced it was delicious... and was instantly given the remaining half. It was a crash course for me in language not being just what we say, but how we say it and also where we say it. It reaffirmed the fact that teaching culture was as important as teaching language. After all, even if a student can say 'Give me some cheese pie!' (a daily request in a Serbian bakery) with perfect grammar and perfect pronunciation, they may find themselves greeted with a 'Sorry?!' by an aghast Gregg's employee on the English high street. Language teaching must include both - language and culture are integral parts of the whole.

\section{Cultural problems faced by students}

This area of English politeness versus Serbian directness is just one of the problems faced by those studying the English language in Serbia today. Another is the fact that the multiculturalism of British society is, in the main, still sadly lacking here. I remember when I first arrived in Belgrade, people would wait for hours for the number 31 bus because one of the vehicles used to service this route was driven by a black man - one of very few, if not the only, non-Caucasian in the city. Upon spotting him driving the bus, they'd board the vehicle, have a good stare and then alight at the next stop. I found it thoroughly bizarre. I also discovered the textbooks being used to teach school children English at that time were very much based on 'white, middle-class stereotypes' with it constantly 'raining cats and dogs' and 'umbrellas being carried' while mother, father and two children were on their way to 'have tea at five o'clock'. I leapt at the chance when asked to co-author a series of textbooks and made sure to include characters from minority ethnic groups and a culture section to introduce Serbian youngsters to some of the common, yet less publicised cultural aspects of modern day Britain. Having said that, 'contemporary Britain' is changing so quickly that such references soon seem outdated, meaning it's crucial that we as teachers keep up-to-date with not only the latest trends when it comes to methodology, but also novelties in terms of language and culture.

A changing aspect of language that I find myself having to, let's say, work at could come under the umbrella of 'political correctness'. It was not much talked about in the mid-90s when I left England, but of course has become all the rage in Britain. 
Students in Serbia still learn about 'policemen' and 'stewardesses' when of course 'police officers' and 'flight attendants' are (at the time of writing) the preferred terms. Some newer terms regarding gender identity, like $\mathrm{Mx}$, ze and hir, are probably many years from becoming commonplace in international English language teaching, but I believe that today's young people, living in a globalised, online world, may end up working for anyone, anywhere and must develop an awareness of such things. What seems strange in this country may well be the norm in another part of the world. I enjoy pointing out the more 'eccentric' aspects of PC (to put it politely), like the word 'blackboard' being banned in schools for the less racially-divisive 'chalkboard' - although both terms are probably now obsolete in $21^{\text {st }}$ century Britain. Add to this the British obsession with 'health and safety' - for example, mortarboards have been banned at many university graduation ceremonies in the UK due to the risk of injury posed by them plummeting to Earth having been tossed into the air, as tradition dictates - and you have a world far removed from current Serbian society.

The material to be used in the classroom must be chosen carefully. It has to incorporate both 'contemporary' language (whether it be PC words or new slang) and 'contemporary' cultural references. After all, I truly believe that modern culture is modern language, modern culture shapes modern language - and not vice-versa. This is not something new - it has been the case throughout history. I encountered many examples of it while studying the social history of Western Europe as part of my History degree from Nottingham University. Maybe today, it is simply more pronounced or, as with everything in our world, changing at a rapid rate. Over time, I have come to realise the importance of project work for learners of any age where they can investigate and compare a myriad of aspects of British culture and language, for example accents and dialects, cuisine, festivals, weddings and funerals, attitudes and approaches to education, religion and the environment. They practise the language through researching and discussing, and crucially, comparing British culture with their own. They seem to benefit far more than working through page after page of a textbook. I suppose it is because they can personalise and internalise their learning experience and also because project work can keep pace with cultural and linguistic changes whereas, as I mentioned earlier, textbooks cannot.

Of course, there are many other difficulties my students face. One is trying to imitate the British style of writing. The flowery style favoured by the Serbs throughout their education system and the succinctness of the Brits are not natural bedfellows and it takes much patience and practice on both the teacher's and students' behalf to adapt. Another is my strictness when it comes to cheating. In England, as a student, I didn't dare cheat - with the threat of expulsion from school or university hanging over you, it simply wasn't worth the risk. There were no second chances - if you got caught, you 
were out. Here though, there seems to be pseudo-strictness when it comes to cheating. You can't of course carry on with the exam, but there are no longer term consequences. And I have to admit that my attitude to cheating has mellowed over time. Not to plagiarism - that's another issue altogether, but when it comes to cheating on tests and exams, the Serbs are so resourceful. In fact, I think it's their resourcefulness that has got them through all the troubles of the past 30 years. One day, when I have time, I'll write a book called ' 100 ways to cheat' because my students are so inventive. In fact, they show imagination that is sadly lacking in the rest of their work. Pens containing rolled up crib sheets, special coats with 'cheating pockets', crib sheets sewn into the hems of skirts, and most bizarre of all was when I caught a girl who had prepared for her exam by carefully writing the vocabulary she needed for the exam in alphabet order on her breasts. It's a long story and the written word doesn't do it justice. Don't get me wrong - I am angry when I catch a student 'in the act', but somewhere deep down, I know that student has a resourcefulness, a creativity and even a nerve that will help them get on in life.

Perhaps one of the major cultural problems any new student of mine encounters is understanding how my mind works. We are all a product of our education and undoubtedly features of the British education system I came through has shaped my ideas and beliefs in terms of learning and teaching - whether it be my attitudes to marking, student-teacher relations, methodology, exams, the school day, or even the purpose of education in general. All this probably makes my approach to teaching slightly different from what my students are used to and it is something that they may take time to grow accustomed to, which is always at the back of my mind. At the heart of my beliefs in terms of university education lies the fact that in England, university was far more than just a place of academia. The social side was so important and I remember all the clubs and societies that were offered to us at Nottingham with fondness and a huge dose of gratitude. The focus in Britain was (I use the past tense as I have been out of that system for too long to know if the same is still true) always on the student as a person. The whole entry process to university was proof enough of this with no entrance exam and academic performance being only a small part of what was required to gain a place on your preferred course. In my time, we completed our UCAS Undergraduate Application form, which included a lengthy section on how we spent our time outside school, our free-time activities, our non-academic achievements. If we were invited for interview, the time was spent discussing us as people with very little mention of school or the academic side of things.

\section{A suggestion for English language teaching in the future}

Following on from this, if our focus as teachers is not on students as academics, but on students as people, then it brings me to what I believe is the greatest problem 
of all both inside and outside the classroom today. And this is something that has only gradually dawned on me. While adding cultural 'splatterings' in my lessons is one thing, there is clearly a fundamental lack of both cultural and general knowledge amongst the majority of my students. They ignore - either unintentionally or, more worryingly, by choice - what is happening not only in the world, but also in their own country. As I grow older and struggle to balance a hectic professional life with helping my wife bring up our three children, I find it harder and harder to remember things! However, I can recall exactly where and when it was that the realisation of this 'ignorance' hit me squarely between the eyes. December $20^{\text {th }} 2016$, classroom 226 , the English Department, Belgrade University. It was a few days after a couple of young teenagers had been arrested for setting a homeless man on fire in the town of Novi Sad and I mentioned the example as it was pertinent to what we were discussing in class. I was completely taken aback by the fact that virtually none of the nineteen, twentyyear-olds in the classroom had any idea what I was talking about. Half jokingly, half in desperation, I threw in, "I suppose you're going to tell me you don't know what happened in Berlin yesterday either." Again, I was met by a wall of blank expressions. One student finally put her hand up and said rather vaguely, "Is it something to do with a terrorist attack at some market?" It was indeed the day after terrorists drove a truck into the Berlin Christmas market, leaving 12 people dead.

For me, this was a 'teaching-changing' moment. How can my students write argumentative essays or give presentations on contemporary topics such as environmental change, crime and education, in their oral exams or translate non-literary texts if they have no awareness of what is happening in the world, no cultural 'markers', no cultural 'reference points'? I actually find it slightly amusing, for want of a better word, that as part of our Contemporary English course at the department we insist on making them read 300-page novels when they are incapable of reading a 300-word newspaper article. And this brings me back to the focus on students as people. I truly believe that we as educators have a duty of care to all aspects of a young person's upbringing, not just their English language skills (or whatever subject it may be that we are teaching them). In the pressure to get through the curriculum, it may be difficult to keep sight of what is surely our ultimate aim - to help form well-rounded human beings.

Therefore, going forward in my university teaching, my focus will be on media projects. Students will download apps on their ubiquitous mobile devices, read articles on a given topic, discuss, critically analyse, write, and compare. We may choose to look at register, slang, the writer's ideas, cause and effect - but it will be 'real English', helping all aspects of their language, but also helping them grow as people. In my opinion, this is the future for language teaching at the tertiary level. There is no need for textbooks. Courses should be fluid and based on real events, discussing real issues, 
using real contemporary language. I spent last year introducing some of these ideas with an initial focus on the variety of British newspapers available online. It was not only encouraging that many students used recent, real life events to support their ideas in their end-of-year oral exam, but also a good majority said that they would start reading the news from now on. In the fast-paced life they lead, the idea of being able to help their language, help their general knowledge, help themselves by spending just a couple of minutes reading a news article while on the bus or sitting in the corridor waiting for their next lesson seems an attractive proposition to these young people, who are far more tuned in than we sometimes give them credit for.

\section{One stage further}

Let me take all this one stage further though. This is where I think the foreign lector has a rather (unintentionally) privileged position. Having grown up in a different system (I am not only thinking of the education system, but cultural system, and system of values and beliefs), he or she or ze (!) can see things from 'outside the box'; in fact, we are almost given a licence to see things from the outside. I was lucky enough to attend a university where the teaching staff realised that history as a degree course was not useful for the majority of participants per se; instead, we were taught life skills through our history course - how to present, how to research, how to think critically - and we learnt how to learn. In Britain, most businesses believe that anyone can be taught to do any job if they have the capacity to learn. My sister for example graduated as a marine biologist, but has worked for British American Tobacco for twenty years, moving from department to department, learning as she goes. In Serbia, too, many German companies are opting to employ German speakers who they then teach the necessary skills to do their jobs rather than taking on those with qualifications in a certain field and trying to teach them German - the first option is seen as by far the most efficient use of time and resources. I even attended a CELTA teacher training course many years ago in Budapest where the trainers said grammar knowledge is not as important as classroom methodology - you simply read up on the grammar you have to teach the night before. So learning how to learn is crucial and it's something I don't think we concentrate on enough in the education system in Serbia.

In addition, university in England, as I've mentioned, was very studentcentred. Professors and assistants were there to guide, help, and point the way. It always felt very student-led (although this probably wasn't the case!). Very rarely were we lectured. We didn't have our heads opened up and information poured in. We were taught how to learn and find the information we needed. We were treated as equals. On the whole, the Serbian system is much more authoritarian, much more theoretical and, sadly, much more mundane at all levels. It saddens me that so few children seem to 
enjoy school. I still remember learning about contour lines as a ten-year-old by making a hill out of papier-mâché according to a map we had been given. It was another of those 'I remember where I was' moments - Mr. Barker, Class 6, Westbrook Lane School... And yet my children learn about road signs by staring at a page in a textbook when there are five perfectly good road signs just outside the school if only they were to glance out of the window.

I recently watched two inspirational TED talks. One by Sugata Mitra, called 'Build a School in the Cloud', discusses how teachers today are here to facilitate learning - young people are perfectly capable of finding out information for themselves if they are provided with the tools and taught how to learn, and encouraged along the way. The other was Ken Robinson's 'Do Schools Kill Creativity?', in which he identifies creativity as the key skill going forward - more important than maths ability for example. Maybe this is why I've grown more tolerant of the creative attempts at cheating I mentioned earlier. But it begs the questions - are we encouraging, are we allowing, are we teaching, are we facilitating our students to be creative?

At this point, I should mention my three elderly relatives - three siblings who actually came to Serbia for my wedding in 2006 and still talk about the wonderful time they had. Aunty Lucy is 86 . She's quite insular and happy just to keep on plodding on with her life. Her views though are stuck in the past. She recently admitted that she doesn't tell anyone I live in Serbia as she's worried what people's reaction might be. Her surname is Bestley, which is quite apt as she believes her way of doing things is the best way. Then, there's Uncle Henry. He is 91. He used to be great fun, but his wife has dementia and he himself is in such bad health that he has given up and is simply waiting to die. And finally, there's Aunty Jane. She is 96 and has just decided to move house. She'd lived with Lucy for 20 years, but realised things weren't working and rather than accepting the status quo, decided she needed a new challenge and new friends, and so moved out. Now she has a new lease of life and is more bubbly than I've known her for a long time.

Which brings us to another nonagenarian... Our English department here at Belgrade University's Faculty of Philology I believe is at a crossroads. The same could probably apply to most educational establishments in Serbia. We have to decide whether we are Lucy, Henry or Jane. Just as learning and adapting to cultures is a twoway experience, as with the coffee-drinking episode I mentioned at the beginning of this paper, where we take the good and bad from both sides, so too is education. We, as teachers, have to be prepared to listen and learn from our students (at any level of education); after all, as I've already said, in today's world learning is crucial.

In my opinion, gone are the days of us teaching what we want and how we want. We might not like it, but we have to do some British 'self-analysis'. The gap 
between youngsters and teachers/parents has I believe never been greater. Young people's brains are completely rewired. The American computer scientist, Alan Kay, stated at a Hong Kong press conference in the 1980s that 'technology is anything that wasn't around when you were born'. After all, fire, the wheel, even chairs were once classed as 'technology', which scarily means that smart phones, tablets, interactive whiteboards are not seen as technology by our students, but just an integral part of everyday living and learning. They can google facts and figures, dates of battles, the Latin names of plants, plots of novels, and mathematical formulae more quickly than we can say them out loud. However, in my experience, what they do struggle with is cause and consequence, something that cannot be found via an internet search engine.

Hand in hand with this goes the reduced capacity for cognitive thinking and behind it, the inability to sit still and concentrate for longer than a few minutes unless they are in control, unless they are inspired (another advantage of 'real life' project work). It is often said that youngsters today think very superficially - this is the reality $\mathrm{TV}$ and Instagram generation where everything revolves around appearance. However, the success of computer programming and robotics schools for children shows that they just need inspiring, they need to be learning something that they feel an affinity to.

I believe that as educators in today's world we need to ask ourselves whether we are really inspiring today's learners. Are we teaching them the 'right' things? Are we helping them acquire the skills they need for wherever contemporary life takes them? Or even more pertinent, as Ken Robinson pointed out in his TED talk, are our learners being given the training, the skills and the knowledge that they will require twenty years into the future? Are we putting too much pressure on our learners, overburdening them with tests, exams and material? After all, rare is the person, whichever generation he or she belongs to, who thrives under such circumstances. Are we evolving as educators or are we imposing our educational experiences on our students, whose aspirations, focus and very way of thinking may be so different from our own and anything educators have encountered in the past? In short, are we making today's educational experience as useful, enjoyable and relevant as it can be?

These questions should provide food for thought for those of us privileged enough to be connected to our 'birthday girl' - the English Department here at the Faculty of Philology, a place I hold very close to my heart, a place that has given me so much in terms of opportunities and experiences, a place where I have encountered some brilliant minds and talents among students and staff alike, a place I only wish the best for. We as a department surely have to listen to our students and adapt. In fact, I believe the same is true for educators at whatever level. We as teachers and adults have to be led by the (often inspiring) minds of young people, while facilitating them and guiding them through the learning process. We have to cut down their workload while 
giving them the freedom to research, to innovate, to critique for themselves. We have to ask them what they want, what they expect and how we can help them achieve their goals. In short, the time has come... we have to throw open the windows, risk being hurt by the promaja; simply put, we have to air the room.

\section{References}

Mitra, S. (2013). Build a School in the Cloud, TED talk. (16 October 2018) $<$ http://www.ted.com/talks/sugata_mitra_build_a_school_in_the_cloud $>$.

Robinson, K. (2006). Do Schools Kill Creativity? TED talk. (16 October 2018) $<$ http://www.ted.com/talks/ken_robinson_says_schools_kill_creativity $>$. 